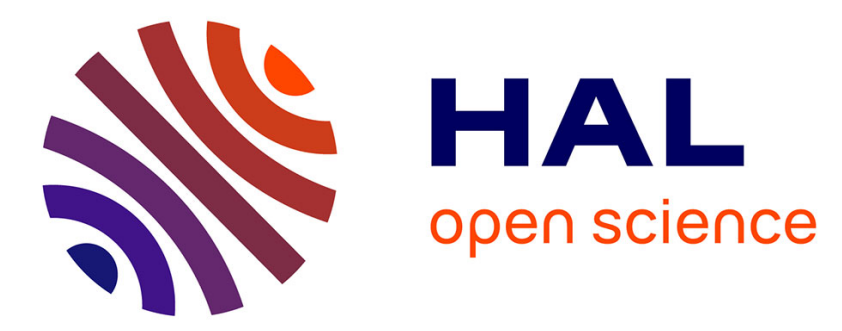

\title{
BOOSTER: Development of a toolbox for triage of large groups of individuals exposed to radioactive material
} Vincent Schoepff, Istvan Almasi, Khalil Amgarou, Frank Becker, Frédérick Carrel, Federico Carvajal, David Gaboriau, Mehdi Gmar, Andras Kelemen, Andras Kovacs, et al.

\section{To cite this version:}

Vincent Schoepff, Istvan Almasi, Khalil Amgarou, Frank Becker, Frédérick Carrel, et al.. BOOSTER: Development of a toolbox for triage of large groups of individuals exposed to radioactive material. IEEE Transactions on Nuclear Science, 2014, 61 (4), pp.2210 - 2216. 10.1109/TNS.2014.2311475. hal-01863369

\section{HAL Id: hal-01863369 \\ https://hal.science/hal-01863369}

Submitted on 18 Dec 2020

HAL is a multi-disciplinary open access archive for the deposit and dissemination of scientific research documents, whether they are published or not. The documents may come from teaching and research institutions in France or abroad, or from public or private research centers.
L'archive ouverte pluridisciplinaire HAL, est destinée au dépôt et à la diffusion de documents scientifiques de niveau recherche, publiés ou non, émanant des établissements d'enseignement et de recherche français ou étrangers, des laboratoires publics ou privés. 


\section{BOOSTER: Development of a Toolbox for Triage of Large Group of Individuals Exposed to Radioactive Material}

\begin{tabular}{|c|c|}
\hline Journal: & IEEE Transactions on Nuclear Science \\
\hline Manuscript ID: & TNS-00496-2013.R2 \\
\hline Manuscript Type: & ANIMMA 2013 \\
\hline Date Submitted by the Author: & $\mathrm{n} / \mathrm{a}$ \\
\hline Complete List of Authors: & 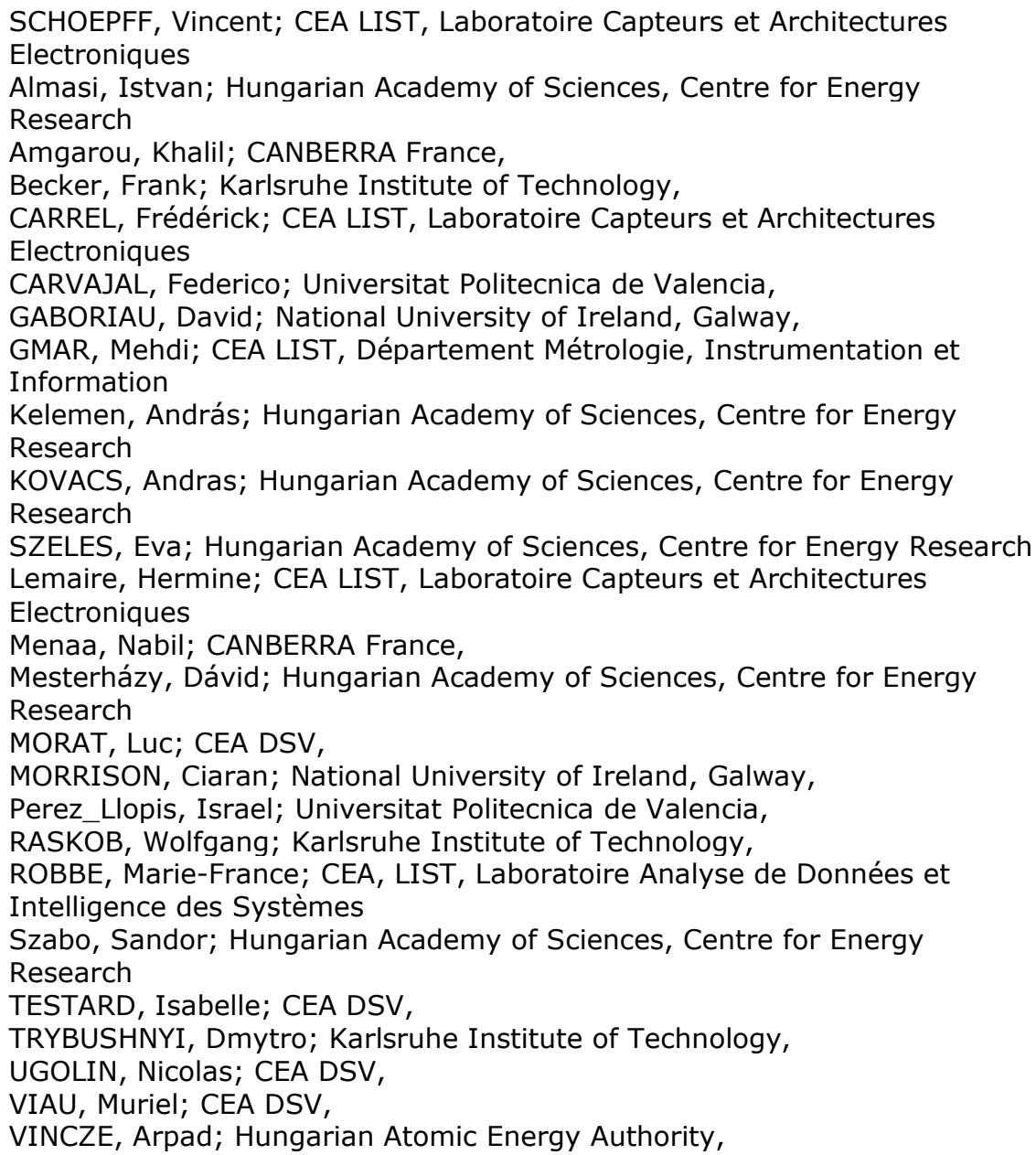 \\
\hline Standard Key Words: & $\begin{array}{l}\text { Decision making, Decision support systems, Dosimetry, Environmental } \\
\text { monitoring, Gamma-ray cameras, Radiation instrumentation, Radiation } \\
\text { monitoring, Safeguards applications, Security applications, Radioactive } \\
\text { pollution, Radiation imaging systems, Miniature radiation cameras, } \\
\text { Gamma-ray spectroscopy, Gamma-ray detectors, Dose rate }\end{array}$ \\
\hline
\end{tabular}




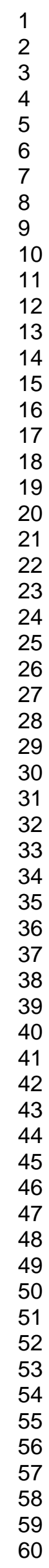

SCHOLARONE ${ }^{m}$

Manuscripts 


\title{
BOOSTER: Development of a Toolbox for Triage of Large Group of Individuals Exposed to Radioactive Material
}

\author{
Vincent Schoepff*, István Almási, Khalil Amgarou, Frank Becker, Frédérick Carrel, \\ Federico Carvajal, David C. Gaboriau, Mehdi Gmar, András Kelemen, András Kovács, \\ Éva Kovács-Széles, Hermine Lemaire, Nabil Menaa, Dávid Mesterházy, Luc Morat, \\ Ciaran G. Morrison, Israel Perez-llopis, Wolfgang Raskob, Marie-France Robbe, Sándor Szabo, \\ Isabelle Testard, Dmytro Trybushnyi, Nicolas Ugolin, Muriel Viau, Árpád Vincze
}

\begin{abstract}
The effective management of an event involving the exposure of a large number of people to radioactive material requires a mechanism for fast triage of exposed people. BOOSTER is a project founded by the European Union under the Seventh Framework Programme, addressing this requirement. It is a capability project designed to provide an integrated system which could easily be deployed and used. For this purpose, the BOOSTER consortium, relying on the expertise of seven members, researches and develops new approaches to allow an effective and fast management of most kind of nuclear threats. BOOSTER System was designed to help first responders mitigate the crisis by providing the necessary information to quickly assess the radiological situation, to support triage staff in performing an efficient and fast categorization of the potentially affected victims, and to give medical staff crucial information for further treatment at medium or long term post-accident.
\end{abstract}

Index Terms - Biodosimetry, Crisis management, Nuclear accident, Radiological attack, Triage, Radioactive pollution.

\section{INTRODUCTION}

$\mathrm{R}$ ecent nuclear accidents, such as the Fukushima event, demonstrated people's fear regarding nuclear risks. Moreover, 9/11 attacks showed the reality and impact of terrorist threat which forced societies to quickly adapt and develop new technological solutions. Large scale terrorist attacks or accidental scenarios, involving a radiological risk,

Manuscript received June 06, 2013. This work was supported in part by the European Commission under Grant SEC-GA-2009-242361.

V. Schoepff, F. Carrel, M.Gmar, H. Lemaire, MF. Robbe are with the CEA, LIST, F-91191, Gif-sur-Yvette, France (email: vincent.schoepff@cea.fr). F. Carvajal and I. Perez Llopis are with the Universitat Politecnica de Valencia, Spain. D. C. Gaboriau and C. G. Morrison are with the National University of Ireland Galway (NUIG), Ireland. I. Almási, S. Szabo, A. Kelemen, A. Kovács, É. Kovács-Széles and D. Mesterházy are with the Centre for Energy Research, Hungarian Academy of Sciences (IKI), Hungary. K. Amgarou and N. Menaa is with AREVA CANBERRA, France. L. Morat, I. Testard, N. Ugolin and M. Viau are with CEA, DSV, F-92265 Fontenay-aux-Roses, France. F. Becker, W. Raskob and D. Trybushnyi are with the Karlsruhe Institute of Technology (KIT), Germany. A. Vincze is with the Hungarian Atomic Energy Authority (HAEA), Hungary. could have dramatic and long-lasting consequences from a sanitary but also psychological point of view.

The effective management of an event involving the exposure of a large number of people to radioactive material, either accidental or following a malevolent use of nuclear material requires a mechanism for fast triage of exposed people. BOOSTER is a project founded by the European Union under the Seventh Framework Programme, designed to provide an integrated system which could easily be deployed. For this purpose, the BOOSTER consortium developed new approaches to allow an effective and fast management of most kind of nuclear threats. Based on an identified scenario of terrorist attack, reflecting the threats likely to be faced, BOOSTER System was designed to help first responders mitigate the crisis by providing the necessary information to quickly assess the radiological situation, to support triage staff in performing an efficient and fast categorization of the potentially affected victims, and to give medical staff crucial information for further treatment at medium or long term postaccident.

In this paper, an overall description of BOOSTER System functionalities for optimizing crisis management following an accidental or malevolent nuclear event is presented. An emphasis is made on the first results obtained for the adaptation of the GAMPIX gamma camera during laboratory tests. In parallel, summary results of other developments and adaptations is presented allowing a first assessment of BOOSTER performances.

\section{ARCHITECTURE OF THE SYSTEM}

\section{A. A system based on current procedures}

The BOOSTER System architecture was imagined to fit current procedures for radiological crisis management. Once any radiological contamination is detected on the site of an event, the BOOSTER System is deployed by the first responders. In addition, the necessary command \& control echelons are established according to the crisis magnitude. 
In the case of the management of a crisis (accident, terrorist attack...), involving nuclear or radiological material, different areas are commonly defined around the scene [1]. These areas are established in order to exclude and guard the dangerous zone for unauthorized people, protect and control the public, and minimize the spread of contamination in surroundings.

\section{Exclusion area and Controlled area}

The Exclusion area is the area directly affected by the event. It is subject to high levels of radioactivity and contamination. In this area only duly protected first responders perform the rescue and manage the evacuation of the victims. These first responders (mainly firemen) deploy several measurement devices belonging to the BOOSTER System in order to gather crucial information that helps for situation assessment and coming triage. With these components of the BOOSTER System, first responders will provide data on radioactivity levels, taken from deployed sensors, get an overview of the situation, establish the Exclusion area and Controlled area perimeters and assess by calculation the dose received by victims by external irradiation, depending on their position at the moment of the incident.

The Controlled area is a secured area surrounding the Exclusion area. Its perimeter is defined according to the dose rate levels (i.e. an area where the dose rate is lower than $0.3 \mu \mathrm{Sv} / \mathrm{h}$ according to IAEA guidelines) [1]. The Controlled area is used as a fallback position for the first responders deployed in the Exclusion area and a safer interface for victims evacuation. The first phase of the triage, which consists in a medical triage determining the level of injuries encountered by victims, is carried out in the Controlled area.

\section{Decontamination area}

Before going out of the Controlled area, and in order to minimize the spread of contamination, victims and involved people (members of emergency services, for instance) are taken to a contamination control checkpoint. If a victim is not contaminated, this person can continue the triage circuit. On the contrary, a decontamination process is applied in the Decontamination area, where several measurement devices are deployed to assess the level and the position of external contamination on individuals.

\section{Support area}

Following the decontamination (if required), a deeper analysis of victims for radiological triage is performed once the affected persons arrive to the Support area. This way, the victim triage is accelerated and each person receives adequate treatment according to their radiological status. Those analyses rely on newly developed biodosimetric tools and tests on either biological samples or belongings originating from victims.

\section{Remote Command and Control area}

This area is located away from the event area; nevertheless several command and control components which compose the first echelons are also located in the other usage areas. All information from the Controlled area as well as second level global information from the Support area is received in the Command and Control area and assists the authorities and higher level crisis managers in mitigating the incident effects and manage the available resources in an optimum way.

\section{B. Overview of BOOSTER system components}

The BOOSTER system was designed to encompass three main objectives: the evaluation of environment radiological situation, the quick on-site first triage of victims and the collection of more precise estimation of medical impact for medium/long term follow-up.

In order to achieve these goals, a set of tools was chosen and designed to provide the necessary information. Table I summarizes the integrated components, their goals and main characteristics. These tools, which will be described in this article, mainly consist in: deployable sensors for situation assessment and first responders information (presented in section III), fast-response on-site methods for the evaluation of dose received by victims in order to perform a first triage in

TABLE I

SUMMARY OF BOOSTER SYSTEM INTEGRATED COMPONENTS

\begin{tabular}{|c|c|c|c|c|}
\hline Technique & Goal & Output & Measured sample & Main characteristics \\
\hline Dose-rate meters & Environmental impact & Dose rate mapping & Environment & Fast, precise \\
\hline HPGe system & Environmental impact & Nuclide identification & Environment & Fast, precise \\
\hline Gamma camera & Environmental impact & Hot spot location & Environment & Fast, precise \\
\hline Contamination portal & Fast triage & External contamination & Whole body & Fast, contamination status only \\
\hline Contamination probes & Fast triage & External contamination & Whole body & $\begin{array}{c}\text { Fast, quantification of external } \\
\text { contamination dose }\end{array}$ \\
\hline $\begin{array}{l}\text { Low-background gamma } \\
\text { spectrometry }\end{array}$ & Fast triage & Internal contamination & Biological & $\begin{array}{c}\text { Fast, estimation of internal } \\
\text { contamination dose }\end{array}$ \\
\hline Portable LIBS system & Fast triage & Internal contamination & Biological & $\begin{array}{c}\text { Fast, estimation of internal } \\
\text { contamination dose }\end{array}$ \\
\hline$\gamma H 2 A X$ quantification & Fast triage & Global irradiation & Biological & Fast, categorization of victim \\
\hline Retrospective dosimetry on SMD & Fast triage & External irradiation & Belongings & Fast, estimation of irradiation dose \\
\hline Liquid scintillation & Off-site analysis & Internal contamination & Biological & $\begin{array}{l}\text { Medium term, precise det. of } \\
\text { internal contamination dose }\end{array}$ \\
\hline LA-ICPMS analysis & Off-site analysis & Internal contamination & Biological & $\begin{array}{l}\text { Medium term, precise det. of } \\
\text { internal contamination dose }\end{array}$ \\
\hline Centrosomes quantification & Off-site analysis & Global irradiation & Biological & Medium term, precise det. of dose \\
\hline Granulometry on particles & Off-site analysis & Toxicity evaluation & Biological & $\begin{array}{c}\text { Medium term, precise det. Of } \\
\text { toxicity }\end{array}$ \\
\hline
\end{tabular}


case of mass casualties (presented in section $I V$ ), and longerterm in-laboratory techniques for more precise determination of radiological exposure for refined medical treatment (presented in section $V$ ).

\section{Compactness, ease-of-use, quickness and scalability}

Due to the particularly difficult work conditions in the Exclusion and Controlled Areas, as explained in section $I I-A$, only duly protected first responders are allowed to operate in this area, the focus is made on the compactness, portability and ease-of-use of the deployed sensors. This portable toolbox allows emergency services to speed up and optimize the first phase of the triage without having to focus their effort toward measurement devices. Therefore, all components were developed or modified in order to be autonomous and easily wearable, or at least easily deployable, by first responders.

In order to speed up the triage process, all in-field analyses were designed to give their results in less than twenty minutes and allow for parallel analyses. As operators carrying out biological samplings (hair follicles, blood, buccal cells...) required for analyses are not necessarily part of the medical staff, sampling material was chosen and especially adapted to be non-invasive. The software architecture is also adapted for use by non-experts. For instance, most sensors are automated for getting the results and feedback information to upper echelons of command and control by themselves.

As no event is comparable to another, the BOOSTER system was designed to be scalable, i.e. the composition of the system can be modified to fit the magnitude of the event. The toolbox was scaled for a given number of affected people. However, it is possible to multiply the toolboxes deployed on the site of the event and to connect all of them to the same Command \& Control and DSS systems to fit the range of casualties.

\section{Coordinated network and interoperability}

Sensor platforms, including a GPS device were developed to be deployed in the affected area. These platforms were adapted to receive each sensor and have the availability to send the gathered information to a coordinated network based on the SIMACOP system developed by UPV [2]. The core software processes the information from sensors and interpolates to get a picture of the radiological situation in the area of interest. It also provides an evaluation of the exposure and contamination status of people, based on the data from deployed sensors and victims' position in the area.

Information from sensors, estimation from software and data from external sources are processed in a decision support system. This decision aiding component supports users in the triage, taking medical, radiological and resources aspects into account. A module allowing the resource management helps optimizing the strategy of application of the system.

A particular effort was made on the interoperability aspects of the software to easily exchange information with existing National Situation Awareness and Decision Support Systems. This interoperability is supposed to allow the integration of
BOOSTER system in the existing crisis management plans and bring accurate information for Authorities of Civil Protection to take informed decisions.

Data transmission between the first level command and control nodes located near the incident site and the second level command and control centers located in a remote location are performed through large bandwidth means (high speed internet connections or satellite).

\section{RED ZONE RESPONSE - INFORMING FIRST RESPONDERS}

As the first phase of BOOSTER System deployment, a fast evaluation of the radiological situation is performed on the scene with newly developed and adapted existing measurement tools. The fusion of this information with the position of people in the scene allows an estimation of the dose received, may it be by irradiation or by contamination means.

\section{A. A miniaturized gamma camera for hot spot location}

As an example of the deployed components, the second generation gamma camera GAMPIX [3], [4], developed by CEA LIST and shown in Fig. 1, was adapted for use by first responders directly in the affected zone. Lightness and compactness of the system are therefore being emphasized along with the system temporal sensitivity.
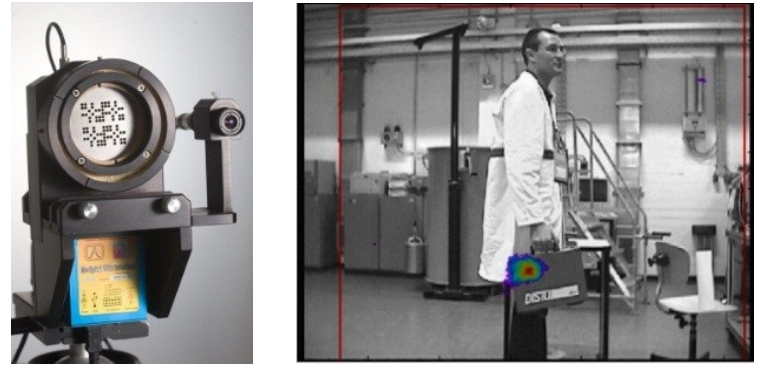

Fig. 1. On the left: current prototype of the GAMPIX gamma camera. On the right: detection of a plutonium sample carried in a piece of luggage.

The principal objective of this gamma camera is to locate the hot spots on the scene so that first responders could be aware of the dangerous areas and avoid them. This application requires, from the camera, to operate in a very large range of dose rates that could be encountered in emergency situations. A characterization of dose rate response of the gamma camera was carried out in a calibration laboratory at Karlsruhe Institute of Technology, Germany. Results on the ${ }^{137} \mathrm{Cs}$ source irradiator showed a good linearity in terms of dose rate assessment from $150 \mathrm{nGy} / \mathrm{h}$ to $23 \mathrm{~Gy} / \mathrm{h}$ for point sources.

Specificities of the gamma camera have also been adapted to the type of radionuclides potentially present in a dirty bomb. Measurements with radiological sources of interest for security application were carried out at the Center for Energy Research of the Hungarian Academy of Sciences, Hungary. Results, some of them presented in Fig 2, showed a good applicability of the gamma camera for a wide range of radioisotopes that could be encountered in the frame of a dirty bomb attack or a large scale radiological accident. It is important to note that the gamma camera was also found suitable with imaging extended sources, such as the Fig 2 uranyl acetate. 
Another application that is currently being studied is the detection of contamination spots on individuals to determine which part of the body might have been contaminated. This second field of use requires a good sensitivity to very low dose rates in addition to a good withdrawal of the ambient radiological noise by hardware and software methods. The sensitivity of the gamma camera was shown compatible with such a fast assessment. A $150 \mathrm{nGy} / \mathrm{h}$ source was imaged in less than 5 minutes.

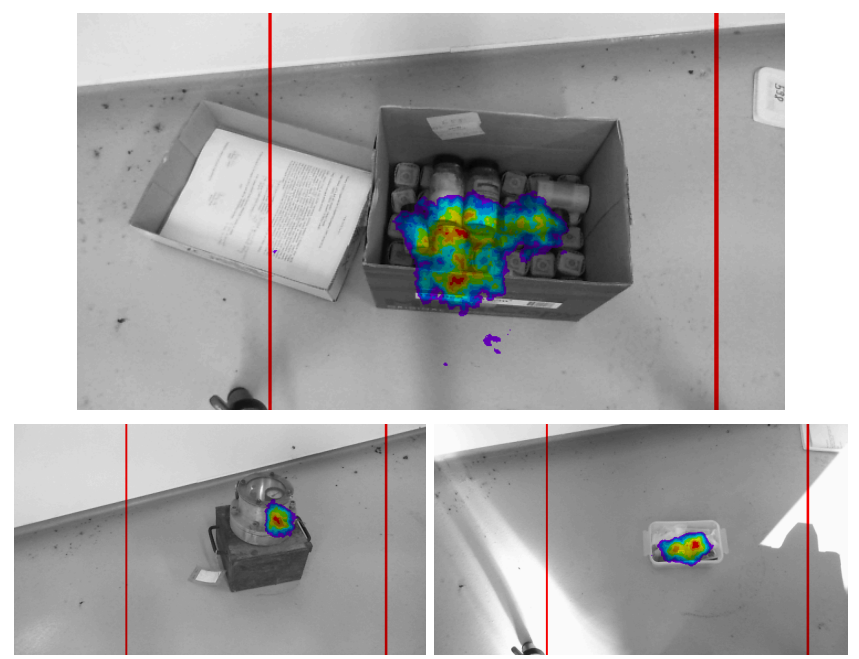

Fig. 2. On the top: uranyl acetate bottles. On the bottom left: plutonium source. On the bottom right: natural uranium bar. Detection duration and sources activities are voluntarily not stated.

Given presented results, the gamma camera was found suitable for both intended uses in the frame of BOOSTER system: first, the location of highly irradiating hot spots, to point out the hazardous areas to be avoided; secondly, the detection of heavy contamination spots on victims, as a prescreen before contamination assessment process.

\section{B. Network of sensors for dose-rate mapping}

In addition to this gamma camera, other sensors were assessed for being deployed over the affected area, allowing the evaluation of the situation. Those sensors, provided by AREVA CANBERRA, include compact dose rate meters equipped with a GPS module for mapping of radiation levels in the Exclusion area and portable HPGe detectors for identification of radionuclides faced [5]. Sensor platforms are adapted to each sensor to send the gathered information to a coordinated network based on the SIMACOP system developed by the Polytechnic University of Valencia, Spain. The core software processes the information from sensors and interpolates to get a picture of the radiological situation in the area of interest. Information from sensors, estimation from software and data from external sources are processed in a decision support system providing an evaluation of the exposure and contamination status of people, based on their position in the area.

\section{MitiGATION - INFORMING TRIAGE TEAM}

\section{A. A unique ID for individuals identification}

Once getting out of the affected area, individuals are given a wristband with a unique barcode ID. This barcode follows the victim during the whole triage process. All analysis results or estimations from sensors are listed under this ID in a specific database that is reachable by triage staff and medical staff at any time for victims follow-up.

\section{B. Tools for characterization of the external contamination}

A complete set of tools was developed or adapted for the characterization of the external contamination. Decontamination tents are equipped with contamination monitoring portals, in order to determine the contamination status of each victim passing through. In case the contamination status turn to positive, the determination of the external contamination is supplemented with cutting-edge detection probes provided by AREVA CANBERRA which allow the detection and location of alpha, beta and gamma emitters. This information, processed by the central software of BOOSTER toolbox therefore allows determining the dose received by external contamination.

\section{Tools for characterization of the internal contamination}

New, lead and iron, low-background spectrometry systems, developed at the Center for Energy Research were made compatible with an in-field use. Those measurements were designed to be carried out on biological samples from victims (urine, saliva, nasal mucus...) to determine the activity of the incorporated gamma-emitting nuclides. Their design, based on several slices of less than twenty kilograms, allows them to be easily transportable in a van and deployed on the field for direct measurements. According to the first test results, the background radiation is decreased by about two to five magnitudes depending on the energy. Under emergency situation the iron chamber and lead container measurement systems should be used in such a location that the staff can operate the system under safe conditions. Based on these preliminary assessment and first measurements results, applying measurements of a few hundred seconds in such locations would lead to detect the presence of gamma radioactive material being under the exemption activity limit. For the most common isotopes, these values are activities from $1 \mathrm{kBq}$ to $1 \mathrm{MBq}$ and activity concentrations from 1 to 1.000 $\mathrm{Bq} / \mathrm{g}$, depending on the isotope of interest. By knowing the activity of radionuclides in the body and the approximate time of incorporation, the total dose received can be estimated. First results obtained with the developed low-background spectrometry system, applied to blood with incorporated isotopes, showed the possibility to detect, among others, down to $15 \mathrm{fg}$ of ${ }^{239} \mathrm{Pu}, 5 \mathrm{ng}$ of ${ }^{238} \mathrm{U}$ or $35 \mathrm{pg}$ of ${ }^{235} \mathrm{U}$.

In parallel, investigations on a portable Laser Induced Breakdown Spectroscopy (LIBS) lead to a detection limit of $242 \mathrm{ppm}$ of ${ }^{137} \mathrm{Cs}$ in urine matrix. All together, these 
measurements allow the determination of the internal contamination of victims, at very low concentrations.

\section{New biodosimeters for quick determination of received dose}

Biodosimetric approaches are frequently focused on cytogenetics. The quantification of the dose from dicentric/ring chromosome scoring appears to be the most precise. Current optimization of such analysis involves the automation of various steps in the process. However, chromosome analyses are performed on the first mitosis post exposure and thus a significant limiting factor remains the culture step of two days that is impossible to reduce. New biodosimeters were developed in the frame of this project to accelerate the triage process.

Irradiation of an individual can be quickly determined by analysis of cellular processes that respond to ionizing radiation effects. Indeed, a major consequence of ionizing radiation is the generation of DNA double-strand breaks [6]. These double-strand breaks induce a rapid and coordinated series of cellular responses, one of which is the phosphorylation of $\mathrm{H} 2 \mathrm{AX}$ histone in large chromatin regions (up to $2 \mathrm{Mb}$ ) surrounding the break. These regions can be detected by immunofluorescence microscopy as subnuclear foci of phosphorylated $\mathrm{H} 2 \mathrm{AX}(\gamma \mathrm{H} 2 \mathrm{AX})$ and the level of $\gamma \mathrm{H} 2 \mathrm{AX}$ foci is proportional to the number of nuclear double-strand breaks. Quantification of $\gamma \mathrm{H} 2 \mathrm{AX}$ thus allows the determination of the radiation dose received by the cells. However, this H2AX phosphorylation is time-dependent and also depends on individual radio-sensitivity. In order to achieve a new biodosimetric method, the property of the histone H2AX was used to develop a quick test to determine the level of irradiation of an individual. The test set up takes into account both the variability of the individual sensitivity and the delay for the observation for each individual. The aim is not only to estimate the dose, but also the risk, in order to define preventive actions, appropriate treatments, and subsequent storage place of the victims.
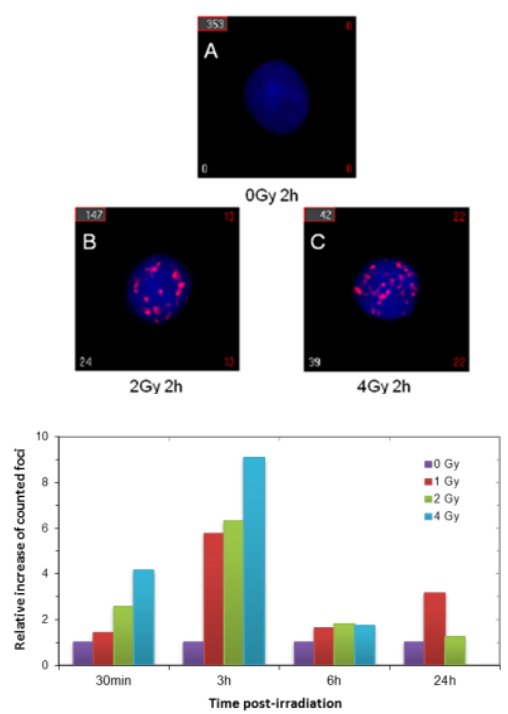

Fig. 3. At the top: follow-up of $\mathrm{H} 2 \mathrm{AX}$ phosphorylation in terms of intranuclear foci for irradiation of $0 \mathrm{~Gy}, 2 \mathrm{~Gy}$ and $4 \mathrm{~Gy}$. At the bottom: scoring of phosphorylated H2AX after immunofluorescence microscopy analysis of human lymphocytes exposed to $1 \mathrm{~Gy}, 2$ Gy and 4 Gy.
The Life Sciences Division of CEA tested the proteins extraction on pig hair and human blood which were irradiated at $0 \mathrm{~Gy}, 2 \mathrm{~Gy}, 4 \mathrm{~Gy}$ and $8 \mathrm{~Gy}$. The phosphorylated histones $\mathrm{H} 2 \mathrm{AX}(\gamma \mathrm{H} 2 \mathrm{AX})$ were quantified by labelling or by direct dosimetry of phosphorus with a LIBS system. It appeared that the $\gamma \mathrm{H} 2 \mathrm{AX}$ level was proportional to the irradiation doses as shown in Fig. 3.

\section{E. Novel retrospective dosimetry on victim belongings}

The main task of retrospective dosimetry is to assess or, if possible, to determine the absorbed dose posteriorly. Thermoluminescence (TL) and optically stimulated luminescence (OSL) are the most important analytical methods used in retrospective dosimetry. It is known, that natural materials such as sodium-chloride, dolomite or calcite, available in the environment, have luminescence properties and can be used for retrospective dosimetry [7], [8]. On the other hand the subservient luminescence properties of surfacemounted devices (SMD) have also been proved previously suitable for retrospective dosimetry purposes [9], [10], [11]. Environmental materials were selected by the Center for Energy Research, for the investigations in BOOSTER project with respect to the characterization of their luminescence properties. Study focused on the complex characterization and application of SMD resistors for retrospective and accidental dosimetry due to their better properties for the purpose of the project. In addition to their very good properties, the main advantage of SMD resistors is their presence in every cell phone. This characteristic is convenient for having access to numerous retrospective dosimeters, since lots of people now have a cell phone.Consequently thermoluminescence properties and dose response of different types of SMD resistors were investigated. Several different types of resistors were investigated and measured. First results of dose response of different SMD resistors are presented in Fig. 4.

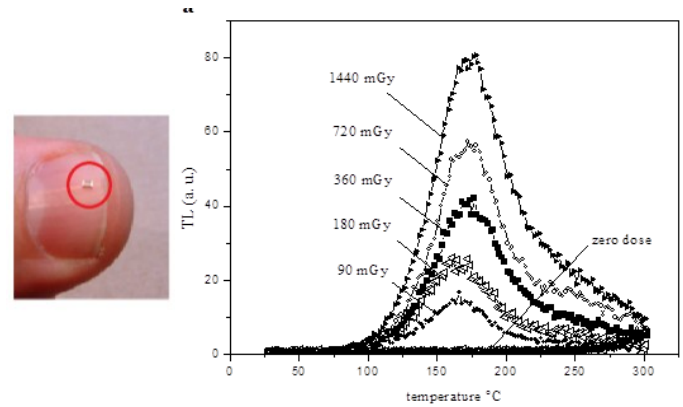

Fig. 4. On the left: picture of a SMD resistor. On the right: thermoluminescence glow curves of 100k type SMD resistor irradiated with different doses

The following parameters of SMD resistors were investigated in the time: thermoluminescence glow curves, dose dependence, reproducibility, fading (stability) and energy dependence. All analysed parameters confirmed the suitability of the SMD devices for retrospective dosimetric purposes. Investigation of other properties (dose rate and temperature dependence, detection limits, etc.) is in progress. 
For laboratory measurements, most of the commercially available devices are suitable and capable to execute all the required steps. However, their physical parameters and design are not favourable for in-field applications. In the frame of the BOOSTER Project, a portable TL/OSL reader was especially designed by Hungarian partners for being used in-field.

\section{F. Decision aiding component for triage}

A software module, developed by the Karlsruhe Institute of Technology, is coupled to the command and control system to help triage teams in their mission and crisis manager to mitigate the situation as quickly as possible. This decision aiding component supports the user in categorising the priority of treatment of individual victims. Factors taken into account can be medical aspects (e.g. trauma patient against radiological exposure), radiological aspects (level of contamination) or resource aspects (number of victims and number of devices). This decision support system is based on the recommendations of the TMT handbook [12].

\section{FURTHER FOLLOW-UP - INFORMING MEDICAL STAFF}

\section{A. Additional biodosimetric tools for refined dose}

As an additional measure at medium-term post-exposure (hours to days), the scoring of centrosomes duplication will help to confirm quickly the victims triage. The levels of centrosome amplification occurring after irradiation were examined by the National University of Ireland, Galway as a biomarker for exposure [13]. New monoclonal antibodies were developed and characterized to quantitate centrosome number using microscopy and then these reagents applied for biodosimetry.

Irradiation caused a linear increase tendency in both the average number of centrosomes per cell from and in the population of cells with amplified centrosomes, confirming our finding that centrosome amplification is a dose-dependent response to DNA damage, as shown in Fig. 5 and Table II. Importantly, this analysis demonstrates that rapid, automated counting is feasible for centrosome quantification as a biomarker. It is also noteworthy that we can feasibly count large numbers of cells using microscopy, allowing improved measurement of centrosome numbers, which we expect to increase the sensitivity of this bioassay.

TABLE II

NUMBER OF CELLS AND CENTROSOMES INCLUDED IN THE CENTROSOME AMPLIFICATION EXPERIMENT

\begin{tabular}{lllll}
\hline \hline $\begin{array}{c}\text { Irradiation } \\
\text { dose }\end{array}$ & Cells & Centrosomes & $\begin{array}{c}\text { Centrosomes } \\
\text { per cells }\end{array}$ & $\begin{array}{c}\text { Percentage of } \\
\text { cells with } \\
\text { more than 2 } \\
\text { centrosomes }\end{array}$ \\
\hline $0 \mathrm{~Gy}$ & 145596 & 19473 & 1.34 & 4.40 \\
$5 \mathrm{~Gy}$ & 5716 & 12388 & 2.17 & 28.52 \\
$10 \mathrm{~Gy}$ & 8336 & 26686 & 3.20 & 50.87 \\
$r^{2}$ & & & 0.996 & 0.999 \\
\hline \hline
\end{tabular}
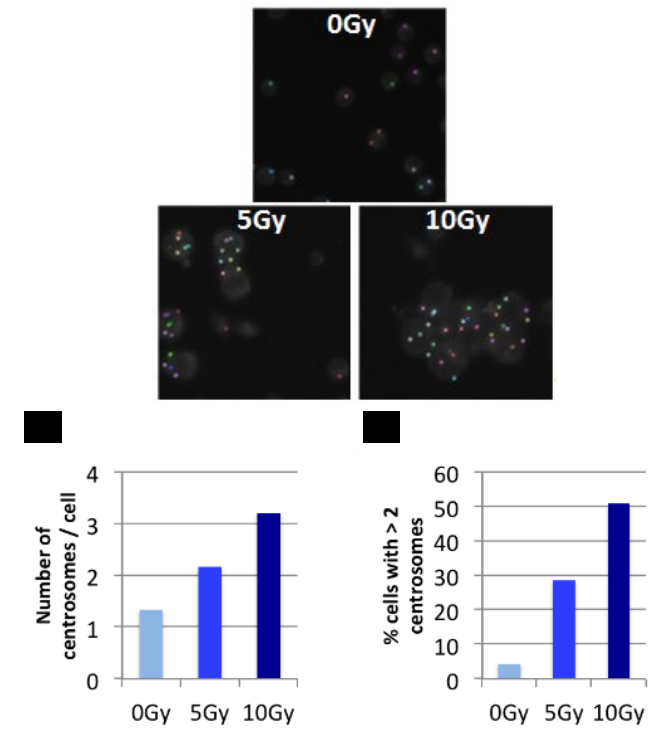

Fig. 5. At the top: counting of amplified centrosomes $24 \mathrm{~h}$ after irradiations at 5 Gy and $10 \mathrm{~Gy}$. At the bottom: quantification of centrosome amplification in DT40 cells after irradiation.

Cells and centrosomes were imaged and quantified with the Operetta imaging system. The average number of centrosomes per cell (Fig. $5 \mathrm{~A}$ ) and the percentage of cells with more than two centrosomes (Fig. 5 B) are shown. The increase in average number of centrosomes per cell and in the percentage of cells with amplified centrosomes correlated positively with the radiation dose $\left(r^{2}=0.996\right.$ and 0.999 , respectively).

\section{B. Granulometry for toxicity assessment}

In addition to the radioactivity of the particles, it is essential to determine their granularity and their nature as, independently of radioactivity, toxicity will depend on the nature and the size of the particle. Small sizes are an aggravating factor, by allowing particles to reach more internal organs. The size of the particles is determined using Rayleigh inelastic diffraction or a simple diffraction, obtained by laser interference.

\section{Laser Ablation Inductively Coupled Plasma Spectrometry for analyses of incorporated nuclides}

Inductively Coupled Plasma Mass Spectrometry (ICP-MS) is used for analysis of radionuclides incorporated in body fluids (saliva, blood and urine). Laboratory-based ICP-MS analyses are performed for more precise determination of the dose after the in-field triage. The analytical protocols which were developed by the Center for Energy Research for environmental and swipe samples were re-optimized for overcoming the potential matrix-related interferences during the analysis. Current methods allow the analysis of uranium and transuranium elements in body fluids; the estimated detection limits based on previous experiences on environmental and swipe samples are in the $\mathrm{fg} / \mathrm{g}(\mu \mathrm{Bq}-\mathrm{mBq} / \mathrm{g})$ range. The use of special sample introduction methods for direct sampling of solid materials by laser ablation allows extending the analytical capabilities of ICP-MS. Employing this method, the incorporation of elements (heavy metals, 
platinum group elements, uranium, etc.) can be investigated in the body. The analysis of a single hair with this approach allows the estimation of not only the time of incorporation, but also the change in the incorporated analyte during a given period.

\section{CONCLUSION AND FORESEEN IMPACT}

The BOOSTER project focuses on developing new biodosimetric tools and integrating them with state-of-the-art measuring equipment and DSS software in a toolbox. The impact of a dirty bomb attack is well known: considerable disruptive effect, forcing public evacuations, creating economic chaos, and inflicting environmental and property damage with significant cleanup costs. The outputs of the BOOSTER project are expected to significantly improve the mitigation capability beyond the state of the art and propose new efficient tools for responders on field.

By performing a very fast triage, with newly developed biodosimetric tools and the complete set of radiological sensors, BOOSTER System allows to discriminate very quickly persons who need to be checked carefully from people who have no medical risks. It will also participate to ensuring that people do not overreact to the mere presence of radiation without full knowledge of the extent and type of contamination.

The new measurement tools also allow securing the first responder from the radiation exposure as these tools do not only check the affected people but also provide clear and comprehensive information on the existing contamination level which is beyond existing radiation equipment available so far.

The prototype of the BOOSTER System was successfully presented during a field trial in May 2013, on KFKI Campus, Budapest, validating the coupling of all devices and showing the applicability of such a system to intended crisis management. It is indeed important to note that even though it was developed for radiological attacks mitigation, the BOOSTER System is also applicable to the management of major accidents in nuclear facilities or transportation emergencies where individuals involved in the transportation and the nearby population might be exposed immediately.

\section{ACKNOWLEDGMENT}

The authors are very grateful to the team of experts and endusers that supported the project and gave their feedback on the system design, documents reviews and to participate to the final in-field exercise in Budapest. We would also like to thank Mrs. S. Pinto-Marques and Dr. M. Müller from Research Executive Agency for their support in the coordination and technical progress of this project.

\section{REFERENCES}

[1] Manual for First Responders to a Radiological Emergency, IAEA, Vienna, 2006.

[2] M. Esteve et al, "SIMACOP: Small Units Management C4ISR System, "Multimedia and Expo, 2007 IEEE International Conference on, pp. 1163-1166, 2-5 July 2007.
[3] M. Gmar et al., "GAMPIX: a new generation of gamma camera", Nucl. Instrum. Methods Phys. Res. A, Vol. 652, pp. 638-640, 2011.

[4] F. Carrel et al., "GAMPIX: A new gamma imaging system for radiological safety and Homeland Security Purposes", Nuclear Science Symposium and Medical Imaging Conference (NSS/MIC), 2011 IEEE, pp. 4739-4744, 23-29 Oct. 2011.

[5] AREVA CANBERRA France website, http://www.canberra.com/fr/.

[6] E. P. Rogakou et al., "DNA Double-stranded Breaks Induce Histone H2AX Phosphorylation on Serine 139", J. Biol. Chem. Vol. 273, pp. 5858-5868, 1998.

[7] I. K. Bailiff, "The use of ceramics for retrospective dosimetry in the Chernobyl exclusion zone", Radiation Measurements 24, Number 4, 507-511, 1995.

[8] L. Bøtter-Jensen, V. Mejdahl: "Retrospective radiation dose reconstruction using optically stimulated luminescence on natural minerals", The proceedings of the international workshop on scientific bases for decision making after a radioactive contamination of an urban environment, IAEA TECDOC, Rio de Janeiro and Goiania, Brazil, IAEA, 1994.

[9] E. L. Inrig, "Retrospective dosimetry using optically stimulated luminescence of electronic components", ProQuest Dissertations and Theses, PhD dissertation, 2009.

[10] H. Y. Göksu, "Telephone chip-cards as individual dosimeters", Radiation Measurements 37, 617-620, 2003.

[11] D. Ekendahl, L. Judas, "Retrospective dosimetry with alumina substrate from electronic components", Radiation Protection Dosimetry 150 (2), 134-141, 2012.

[12] TMT Handbook, Carlos Rojas-Palma et al., NRPA, Norway, 2009.

[13] E. Bourke et al., "DNA damage induces Chk1-dependent centrosome amplification”, EMBO, Rep. 8, p. 603, 2007. 